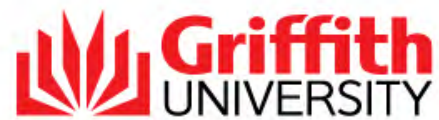

Griffith Business School

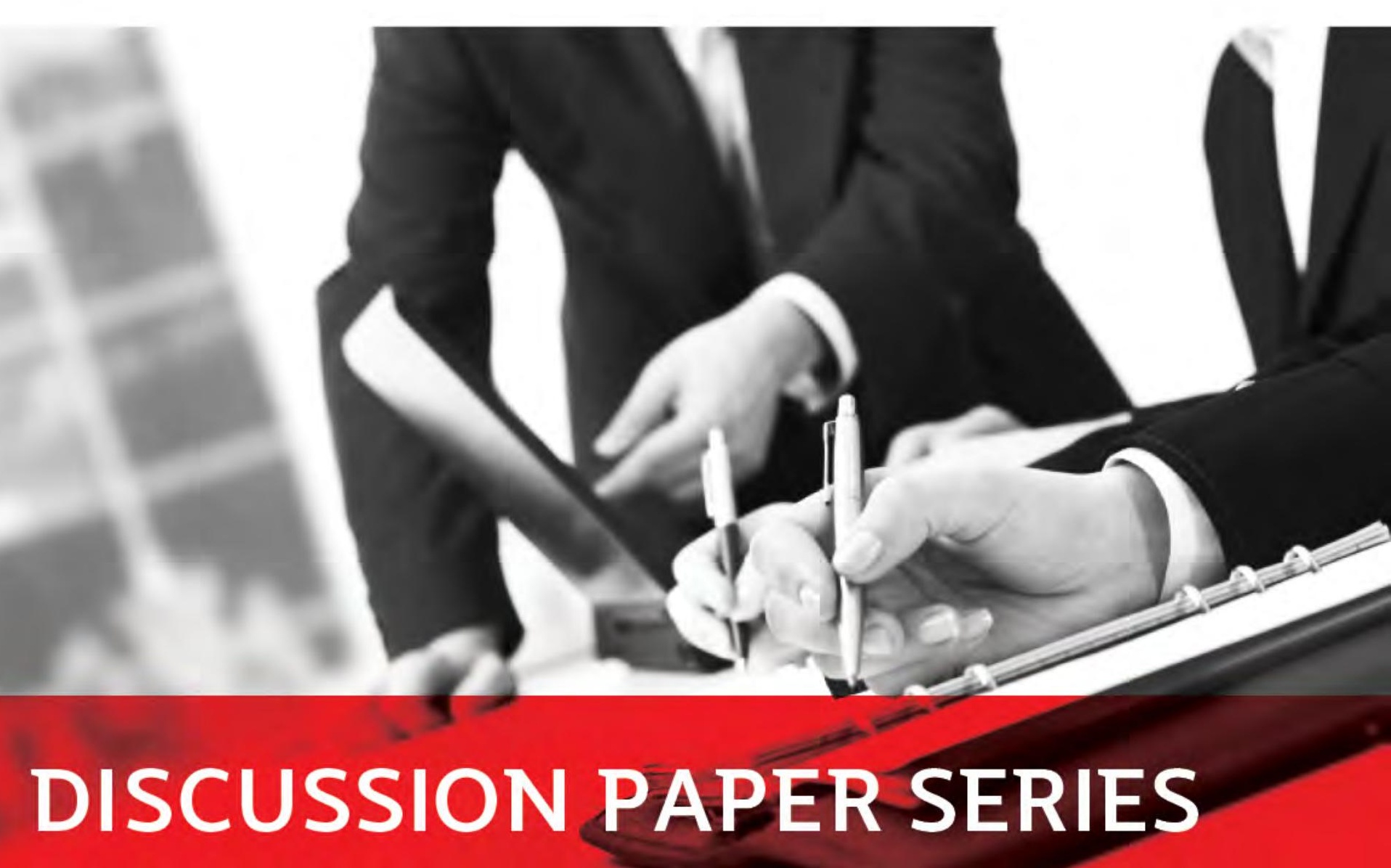

Economics and business statistics

Subprime mortgages and banking in a DSGE model

Martino N Ricci and Patrizio Tirelli

No. 2017-09 


\title{
Subprime Mortgages and Banking in a DSGE Model
}

\author{
Martino N. Ricci* \\ University of Milan \\ Patrizio Tirelli ${ }^{\dagger}$ \\ University of Milano Bicocca and Griffith University
}

\begin{abstract}
Can a DSGE model replicate the financial crisis effects without assuming unprecedented and implausibly large shocks? Starting from the assumption that the subprime crisis triggered the financial crisis, we introduce balance-sheet effects for housing market borrowers and for commercial banks in an otherwise standard DSGE model. Our crisis experiment is initiated by a shock to subprime lending risk, which is calibrated to match the observed increase in subprime delinquency rates. Due to contagion of prime borrowers and to the ensuing adverse effect on banks balance sheets, this apparently small shock is sufficient to trigger a decline in housing investment comparable to what was observed during the financial crisis. The adverse effect of subprimers risk on commercial banks' agency problem is a crucial driver of our results.
\end{abstract}

Keywords: Housing; Mortgage default; subprime risk, DSGE.

JEL Codes: E32, E44, G01, R31.

*martino.ricci@unimi.it

†patrizio.tirelli@unimib.it 


\section{Introduction}

The 2007-2009 financial crisis renewed interest in banking crises, which are rare events typically associated with a prolonged decline in output and employment Cerra and Saxena (2008). One of the main casualties of the financial crisis was faith in standard DSGE models, such as Smets and Wouters (2007) which could not rationalize the crisis without imposing unprecedented large shocks.

The empirical DSGE literature incorporating non-trivial financial frictions and a banking sector has been rapidly expanding since the outset of the financial crisis. BrzozaBrzezina and Kolasa (2013) find that modelling financial frictions is essential for replicating fluctuations in financial variables, but this is not sufficient to improve over the statistical fit of the workhorse New Keynesian model. Similar conclusions are reached in Suh and Walker (2016) and Lind et al. (2016). Boissay et al. (2016) show that a quantitative macroeconomic model characterized by an heterogeneous banking sector can account for financial crises which are rare episodes of credit booms gone wrong, consistently with some common features of financial crises emerging from empirical evidence in a panel of developed countries over nearly 140 years. Their narrative of banking crises is admittedly stylized and inevitably abstracts from specifics of crisis episodes. For instance, this seems to be the case for the exceptionally severe 2007-08 crisis, which was deeply rooted in the sharp increase in mortgage lending and households' debt (Diamond and Rajan, 2009) (figure 1).

According to a popular wisdom (Justiniano et al., 2015), the crisis had its epicenter in the housing residential market and it featured subprime borrowers as the main protagonist along with the banks which had been responsible for the widespread availability of subprime mortgage contracts. One important feature of the crisis was that securitization of mortgage loan could not insulate banks from increased subprime risk. As pointed out in Adrian and Shin (2010), securitization increased the fragility of the financial system by allowing banks and the shadow banking system to raise their leverage by buying each other's securities. In fact, defaults on mortgages spread to investment banks and commercial banks through a sophisticated network of derivatives. As a consequence of increased mortgage delinquencies even traditional banks eventually recorded heavy losses on their balance sheet and suffered severe losses in their net worth. The ensuing turmoil in the financial sector led to a tightening in financial conditions and to a recession which was 


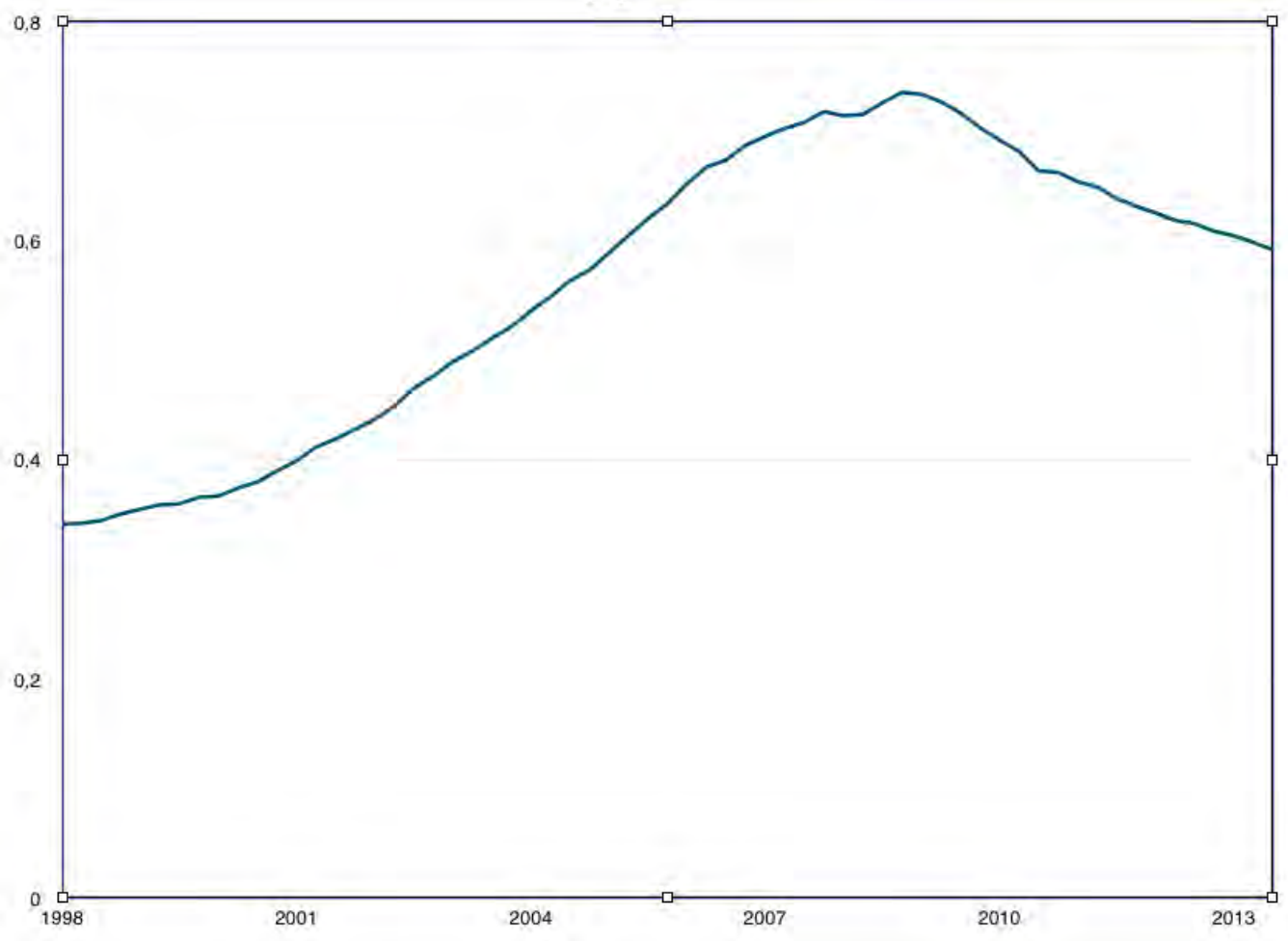

Figure 1: Mortgage to GDP in the United States

extremely severe in the housing market (Figure 2).

The growth of the subprime market started back in mid 1990s (Chomsisengphet and Pennington-Cross, 2006). ${ }^{1}$ However, while between 1996 and 2003 the subprime mortgage market accounted on average for only $9 \%$ of total market, this share more than doubled in 2006, reaching the unprecedented level of $23.5 \%$ (see figure 3). Before the unfolding of the crisis, subprimers default rate was close to $6 \%$, compared to a rate of default of primers lower than $1 \%$, then it climbed to unprecedented levels (figure 5). To explain the US financial crisis it seems therefore important to understand how a shock that originates in this market segment affects the rest of the economy through its impact on the financial sector.

Our modelling strategy is based on a two-sector (housing and consumption goods) DSGE model where agency problems characterize both the bank-

\footnotetext{
${ }^{1}$ The alternative Mortgage Transaction Parity Act in 1982 is the official starting date for the subprime sector.
} 

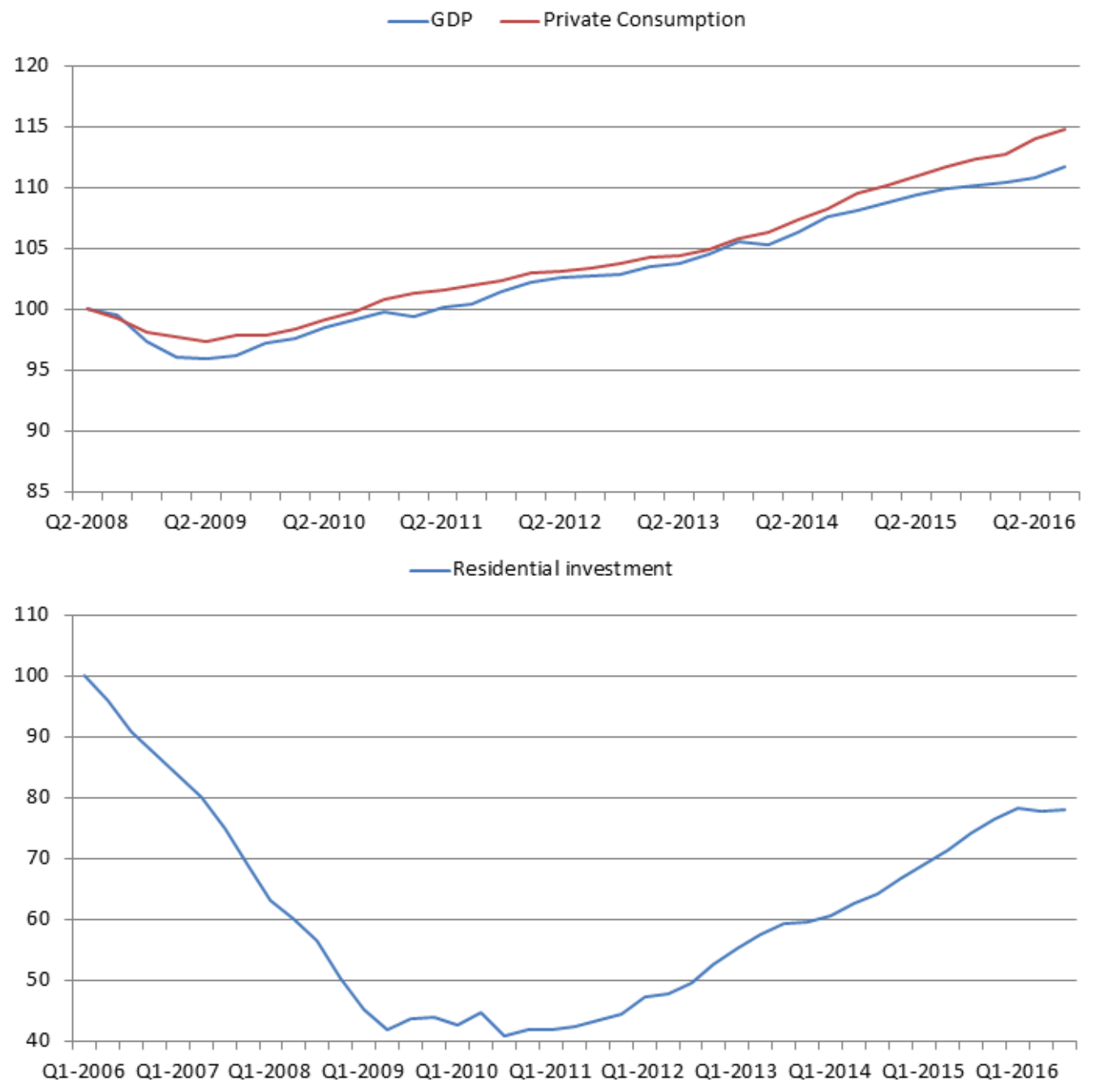

Figure 2: The U.S. during the Great Recession - Federal Reserve Economic Data - FRED - St. Louis Fed. - Quarterly data of: Real Private Residential Fixed Investment, Real Personal Consumption Expenditures, and Real Gross Domestic Product. GDP and consumption=100 in Q2-2008, residential investment $=100$ in Q1-2006.

borrower and the saver-bank relationships. The crisis episode is initiated by a perceived increase in the risk associated to subprime lending which is calibrated to match the observed increase in subprime delinquency rates. This initial shock is then transmitted to the rest of the economy through its effect 


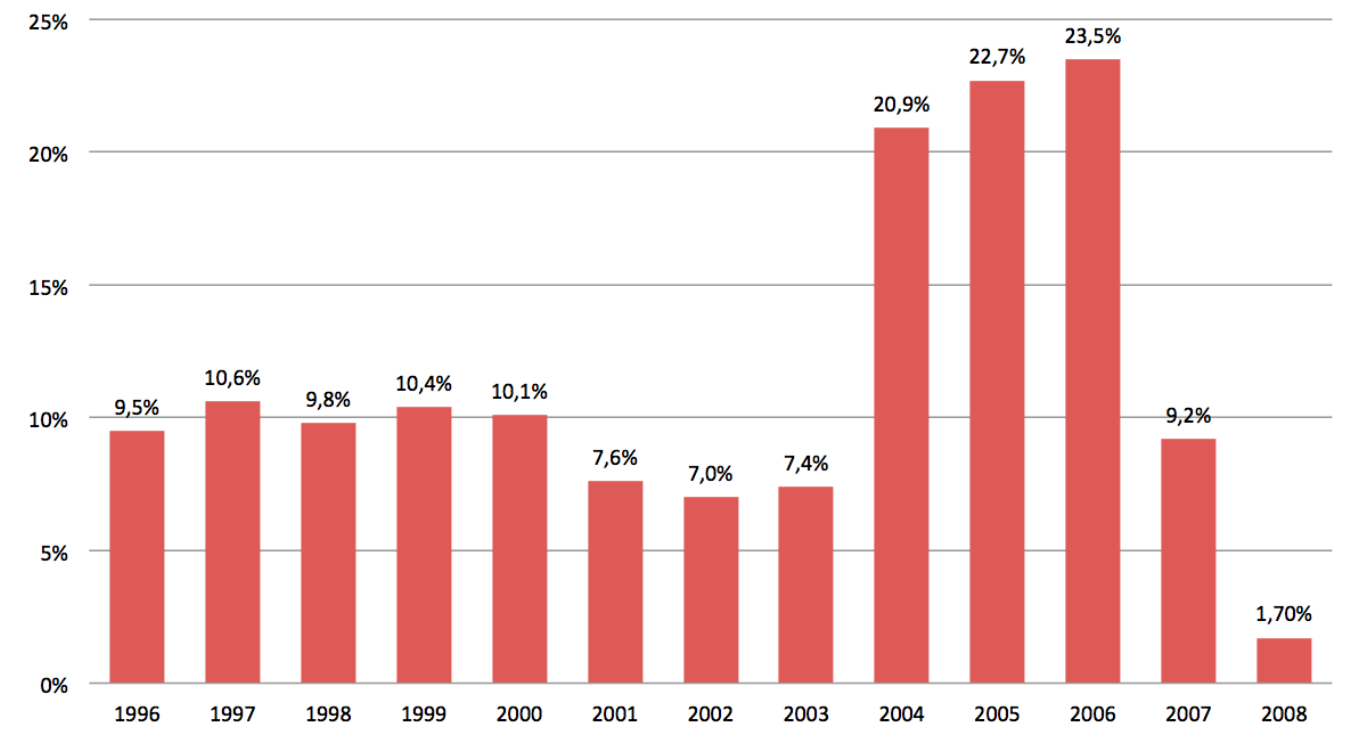

Figure 3: Share of subprime mortgages over the total mortgage market. Source: The Financial Crisis Inquiry Report 2011.

of the banking sector, which is modelled as in Gertler and Karadi (2011) (hereafter GK). The idiosyncratic risk in subprimers housing investment allows us to single out a specific source of shock, which - to our knowledge has never been analyzed in the presence of a non-trivial banking sector. The rest of the model is relatively standard, we incorporate consumption habits, nominal rigidities and housing production adjustment costs as in Carlstrom and Fuerst (2010), but we abstract from accumulation of physical capital.

We claim the following contributions. A shock to the relatively small group of subprime borrowers, which raises total delinquency rate in the housing market from $6.2 \%$ to $16.4 \%$, is sufficient to trigger a large decline in housing investment because of endogenous propagation channels. The effects of the shock are so large that the interest rate, driven by a standard Taylor rule, falls very close to the zero lower bound. Thus, in contrast with popular wisdom we are able to show that a relatively small shock can mimic the financial crisis episode even in a relatively standard DSGE model.

We show that the amplification mechanism works mainly via a worsened agency problem in the financial sector, and sticky bank rates further amplify the shock. Right from the outset it is important to stress that in our model the transmission is particularly large if the subprimer risk shock is also cor- 
related to a shock to the net worth of banks. This assumption mimics what occurred during the crisis, when the subprime crisis led to the collapse of the banking sector stock value (figure 4 ). Furthermore it is interesting to compare our results with Gerali et al. (2010), who find that a bank capital loss per se cannot replicate the amplitude of the 2007-2008 downturn, whereas in our model the combined shock and the associated transmission mechanism have dramatic implications.

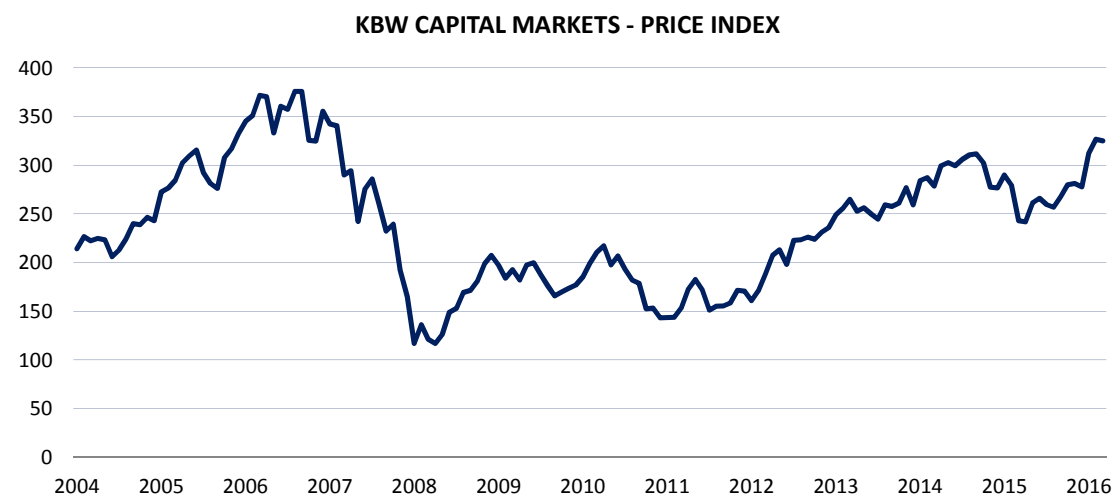

Figure 4: KBW Bank Index. Source: Datastream.

The choices we made in our modeling strategy allow to overcome the limited role that financial frictions seem to play in previous contributions that inspired our work here. In particular, we follow (Forlati and Lambertini, 2011) (hereafter FL) for the introduction of the agency problem on the borrowers side, although we add on their work by explicitly modelling primer and subprimer borrowers. This, combined with the inclusion of a financial sector, allows to overcome their conclusion that the increase in debtor risk has limited effect on GDP. Similarly, GK who neglect the agency problem for borrowers, can mimick the crisis only by assuming an adverse capital quality shock which is almost equivalent to a productivity shock.

The rest of the paper is organized as follows. In the next section we discuss the literature related to the paper. Then, section 3 contains the description of the model, where we describe in details the intermediaries and the households problem, and outline the structure of the model economy. Section 4 presents the benchmark calibration for the model, which is based on U.S. data and on the related literature. Finally, section 5 discusses the results of the crisis experiment that we undertake, and section 6 concludes. 


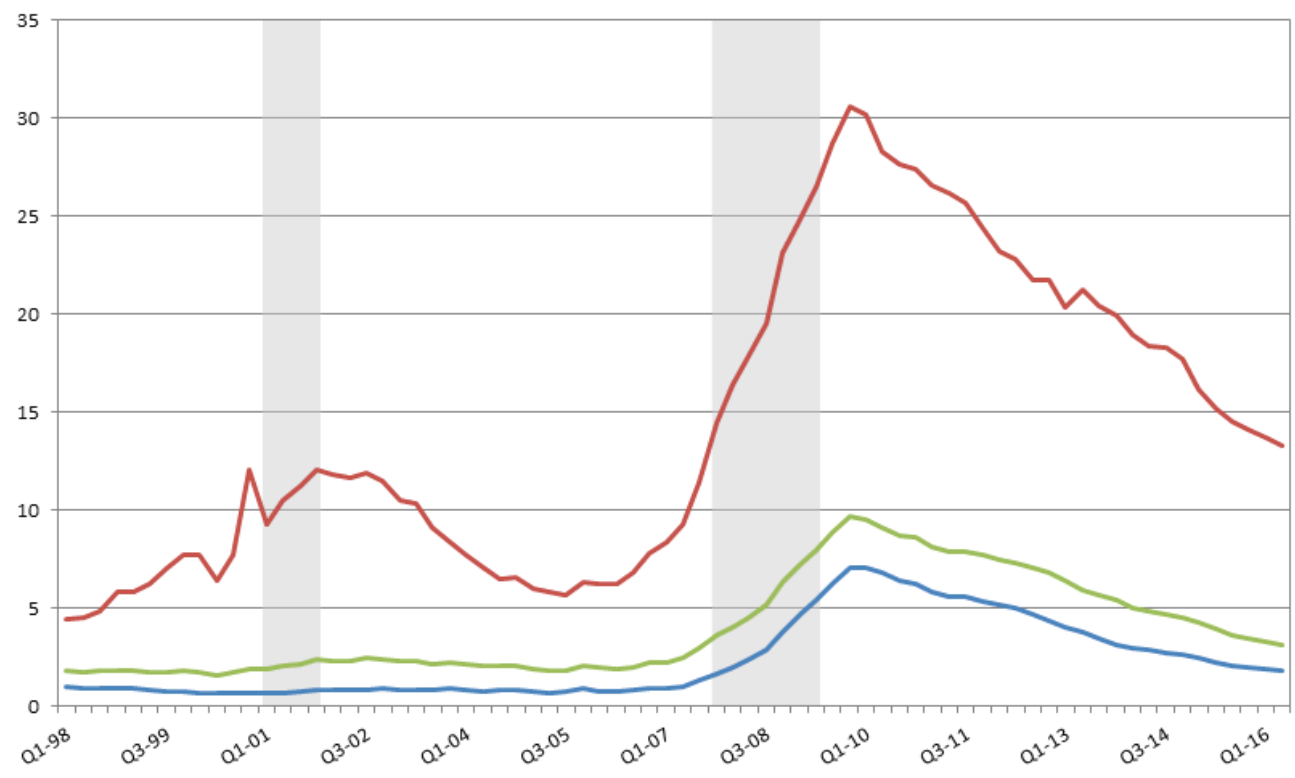

Figure 5: Delinquency rates by loan type - Seriously Delinquent Loans, 90+ days past due - National Delinquency Survey Data - Mortgage Bankers Association.

\section{Literature Review}

The literature on financial frictions is particularly vast but the integration of financial frictions into general equilibrium models of the New-Keynesian types begun only with the seminal contribution by Bernanke et al. (1999) (hereafter BGG). The authors built on Carlstrom and Fuerst (1997) and Bernanke and Gertler (1986), and quantified the relevance of balance sheet constraints on the firms level in determining the propagation and persistence of shocks over the business cycle. A second important strand of literature on financial frictions moves along the lines of Kiyotaki and Moore (1997), who studies the effects on the economy of introducing collateral constraints based on the presence of durable goods. Nested in this strand of research are DSGE models featuring housing production as a specific sector, such as Iacoviello (2005) and Iacoviello and Neri (2010) who estimated a NewKeynesian model with housing for the U.S. economy. Our contribution is indebted to FL, who transfer the agency problem used by BGG to characterize entrepreneurs to the household side. The agency problem is built on the riskiness of housing investment, on households' defaulting possibilities 
and on the fact that the outcome of the investment is private information of borrowers. As in BGG, FL use the Costly State Verification approach, pioneered by Townsend (1979). The presence of monitoring costs justifies a debt contract characterized by a risk premium and an endogenous loan to value ratio (LTV). The framework of FL has been used by Pataracchia et al. (2013), who included the endogenous LTV approach in a large policy model estimated on the Euro Area.

Some contributions have begun to include subprime borrowers into a DSGE model. Justiniano et al. (2016) introduce subprimer borrowers and distinguish them from primers on the basis of their income level. Grodecka (2016) considers also subprime borrowers in a DSGE model, and does so by distinguishing them from primers by assuming that the latter get fixed

rate mortgage contractswhile the former can only get flexible rate mortgage contracts. Our modelling strategy is different and rests on the assumption that subprimers and primers have a different attitude towards defaults, and therefore subprime mortgage contracts are characterized by higher contractual rates. We explain our approach in details in the next section.

For our purposes, another important development is the incorporation of a non-trivial banking sector in DSGE models. In particular, this work builds on GK, who introduce a standard agency problem between borrowers and lenders, which imposes a constraint on the bank rather than on the final borrower. The constraint creates a wedge between the cost of external finance and the opportunity cost of financing an activity with bank's internal resources. This wedge affects borrowers' final credit conditions. The financial accelerator mechanism in this framework works via the banks' net worth, the counter-cyclicality of this wedge derives from the balance sheet of the bank and it is key in unraveling the crisis as it increases the cost of credit when a negative shock hits the economy.

\section{The Model Economy}

The economy is populated by a continuum of infinitely-lived households distributed over the $[0,1]$ interval, each household being composed by a large number of members. Households crucially differ in their rate of time preference. A fraction $\xi$ is impatient while the remaining fraction $(1-\xi)$ is composed by patient individuals. Patient households, i.e. the savers $(s)$, 
lend to impatient ones, i.e. the borrowers $(b)$.

Borrowing is constrained by the value of available collateral, represented by the individual housing stock. The constraint originates from an agency problem between borrowers and lenders which is explicitly modelled. Each household member is subject to an idiosyncratic shock $\omega_{t}^{\iota}$ to the value of his investment. This introduces the possibility of debtor default. The idiosyncratic shock is private information of the investor and it is assumed to be independently and identically distributed (i.i.d.) across members of the same household and across time. $\omega_{t}$ follows a log normal distribution with p.d.f. $f_{t}\left(\omega_{t}\right)$, a cumulative distribution function $F_{t}\left(\omega_{t}\right)^{2}$ and $E_{t}\left(\omega_{t}\right)=1$ and a standard deviation $\sigma_{\omega, t} \cdot{ }^{3}$

Although the narrative of the crisis emphasizes the role played by subprime borrowers, there is no agreed definition of what a subprime loan really is and which borrower types they are meant for. According to the Federal Reserve Bank of San Francisco (2007), subprime is a label attached to a loan by the lender when the borrower has a bad credit history, low credit scores and/or low down-payments or lacks some of the documentation required. However, Demyanyk and Hemert (2011) showed that the idea that subprime loans were given only to credit impaired borrowers is a myth, and that the subprimer group was composed by borrowers of all types. Similarly, Foote et al. (2016) document that the expansion of the subprime market did not entail a significant variation in the distribution of mortgage debt with respect to income. One of the reason for this is that subprime was a label often attached for some intrinsic characteristics of the loan itself rather than for the credit condition of the borrower. ${ }^{4}$ This consideration is important for our modelling strategy of subprime borrowers behavior, which does not rely on income inequality.

The starting point to discuss households' defaulting possibilities is to consider the put option component of the mortgage (Bajari et al., 2008). Models that consider endogenous default possibilities typically assume that i) defaults are strategic, i.e. they occur when it occurs even if the borrower

\footnotetext{
${ }^{2}$ We follow BGG by imposing a restriction on the hazard rate $h(\omega)=\frac{F(\omega)}{1-F(\omega)}$. Namely that: $\frac{\partial \omega h(\omega)}{\partial \omega}>0$

${ }^{3}$ We can safely ignore the effect of the shock on savers because there is no housing risk at the household level savers do not borrow and therefore never default.

${ }^{4}$ For example, the " $2 / 28$ hybrid" mortgage loan was a mortgage contract not usually sold as a prime loan and therefore only available in the subprime market notwithstanding creditors scores.
} 
could still pay back the mortgage but gets higher welfare from defaulting; ii) defaults occurs whenever the equity value turns negative, according to the "ruthless defaulting condition". However, the literature on mortgage defaulting decisions also refers to additional defaulting costs and to concern for fairness and morality (Guiso et al., 2013). Indeed, Foote et al. (2008) show that in the recession of 1990-1991 in Massachusetts only $6.4 \%$ of homeowners decided to default even if they were in a negative equity position.

Our borrower types are characterized by the same discount factor and default strategically, but have different attitudes towards defaulting. While a fraction $(1-\vartheta) \xi$ of subprime borrowers, $(b=s p)$, takes defaulting decisions following a ruthless negative equity condition, the remaining $\vartheta \xi$ primers, $(b=p)$, attach a relatively higher value to their housing investment and exercise the defaulting option at a lower threshold. To obtain this, we assume that primers bear an additional defaulting cost, stigma, which admittedly is a catchall variable which ensures that the subprimers default rate is relatively higher in steady state. This, in turn, allows to obtain different LTV ratios and risk premia for the two borrowers groups.

Banks collect deposits from savers and lend to impatient households. Following GK, lending takes the form of a one period contract, where a statecontingent contractual interest rate $r_{t}^{k}$ is paid each period by non defaulting borrowers to ensure that the banks get a safe return $\left(r_{t}^{l}\right)$, therefore the risk is entirely borne by borrowers. Banks can perfectly discriminate between the types of borrowers, but the realization of the idiosyncratic shock is household's private information and to observe it the lender must pay an auditing cost that is a fixed proportion $\mu$ of the housing stock value. This agency problem introduces a first financial friction in the model since borrowers are endogenously constrained in the amount they can borrow from banks. ${ }^{5}$ If a household's member decides to default the bank can seize the housing stock of the agent, after having paid the monitoring cost. Given that in our model we consider one period contracts, we introduce some sluggishness in lending rates. Following Gerali et al. (2010) we draw a distinction between wholesale banks, that collect deposits, and retail banks, that differentiate funds received from wholesale banks and supply differentiated loans to borrowers.

\footnotetext{
${ }^{5}$ As explained by FL, the shock can be thought of as a shock to the investment itself or as a shock to the price of houses, given by geographical differences. Considering the nature of the shock, which displays an unchanged mean productivity of housing investment, we can also think about it as an increase in uncertainty that endogenously triggers a higher number of defaults in the housing sector (Pataracchia et al., 2013).
} 
Sluggishness arises because we assume adjustment costs for retail lending rates.

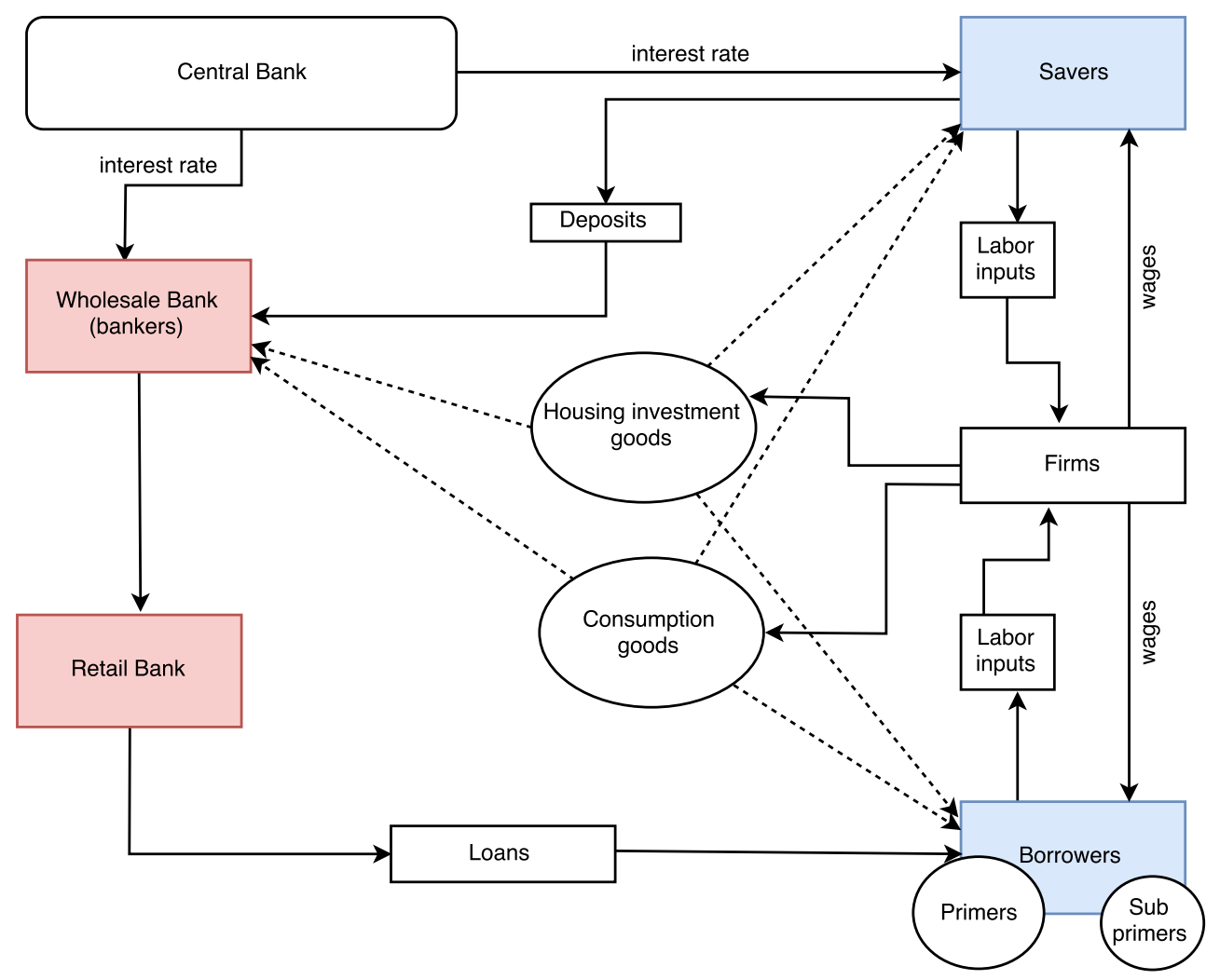

Figure 6: Stylized description of the model.

The rest of the model is a standard two sector DSGE model, where goods are produced using labor-only technlogy, nominal rigidities characterize both price and wage-setting decisions. The interest rate policy follows a standard Taylor rule. Figure 6 outlines the structure of the model.

\subsection{Preferences}

Households preferences are: 


$$
E_{0} \sum_{t=0}^{\infty} \beta_{\imath}^{t}\left(\ln X_{t}-\zeta_{\imath} \sum_{m=c, h} \frac{N_{m, t}^{(1+\eta)}}{(1+\eta)}\right), \imath=(b, s)
$$

where:

$$
X_{t} \equiv\left[(1-\alpha)\left(C_{t}-b_{h} C_{t-1}\right)^{\frac{\left(\chi_{2}-1\right)}{x_{\imath}}}+\alpha H_{t}^{\frac{\left(\chi_{2}-1\right)}{\chi_{\imath}}}\right]^{\frac{\chi_{\imath}}{\left(\chi_{\imath}-1\right)}}
$$

is as an index of housing and non-durable goods, and $N_{m, t}$ defines working hours which are indexed given that we distinguish between employment in the consumption $(c)$ and housing $(h)$ sectors. The parameters $\alpha$ and $\chi_{\imath}$ respectively represent the share of housing in the composite index and the elasticity of substitution between consumption and housing. $\eta$ is the inverse of the wage elasticity of labor supply and $b_{h}$ defines external consumption habits. $\beta_{\iota}^{t}$ is the discount factor and $0<\beta_{b}^{t}<\beta_{s}^{t}<1$, that is, savers discount the future less heavily than borrowers.

Household members can supply labor in different sectors and therefore earn different wages. Furthermore, bankers accumulate their net worth until they exit the market. To avoid further complications, we assume full risk sharing within the household, so that consumption of non-durable goods and of housing services are ex post equal across all members of the household.

\subsection{Financial Intermediaries}

Banks are divided into two distinct branches: a wholesale and a retail one. This modelling strategy is chosen in order to facilitate the introduction of loan rate stickiness in the model. In particular, while the wholesale branch operates under perfect competition, the retail branch operates into a monopolistic competitive market, which allows it to set the loan rate as a markup over the wholesale rate, but loan rate adjustment is costly for the retail bank.

\subsubsection{Wholesale branch}

Our non-trivial banking sector is modelled as in GK. Each household $s$ incorporates a fraction $1-\tau$ of individuals acting as workers, and $\tau$ individuals are bankers that operate the wholesale banks. Bankers may choose to divert a fraction $\phi$ of available funds from the bank portfolio because, by assumption, $\phi$ defines the unit cost savers must bear to recover diverted funds. The agency problem generates an equilibrium spread between bank deposit rates 
and their lending rates, and ties the level of deposits and credit flows to the net worth of banks. There is a fixed probability $\sigma_{b}$ that bankers continue to perform their role in the following period. Conversely, bankers exit from the financial sector and become workers with probability $\left(1-\sigma_{b}\right) .{ }^{6}$ Due to the interest rate spread, bankers keep accumulating wealth until they exit the market. Exiting bankers transfer the accumulated net worth to their household. Households provide new bankers with start-up funds.

At the end of period $t$ the $j$ - th banker's balance sheet is given by:

$$
L_{j, t}=D_{j, t}+N W_{j, t}
$$

where $L_{t}^{j}$ is the amount of claims on retail banks, $D_{j, t}$ defines households' deposits and $N W_{j, t}$ is the banker net worth at the end of period $t$. All variables entering the banker's balance sheet are defined in terms of official goods.

The banker, charges a net real interest rate $r_{t}^{\text {int. }}$ on loans to retail banks, and pays a net real return $r_{t}^{f}$ on households deposits.

The evolution of a surviving banker's net worth is

$$
N W_{j, t+1}=\left(r_{t}^{i n t .}-r_{t}^{f}\right) L_{j, t}^{W}-\left(1+r_{t}^{f}\right) N W_{j, t}
$$

The banker will maximize the discounted value of expected terminal wealth, $V_{j, t}$.

$$
\begin{aligned}
& V_{j, t}=E_{t} \beta_{s} \frac{\lambda_{j, t+1}}{\lambda j, t}\left[\left(1-\sigma_{b)}\right) N W_{j, t}+\sigma_{b} V_{j, t+1}\right]= \\
= & E_{t} \sum_{i=0}^{\infty}\left(1-\sigma_{b}\right) \sigma_{b}^{i} \beta_{s}^{i+1} \frac{\lambda_{j, t+1}}{\lambda_{j, t}}\left[\left(r_{t}^{i n t .}-r_{t}^{f}\right) L_{j, t+i}+\left(1+r_{t}^{f}\right) N W_{j, t+i}\right]
\end{aligned}
$$

where $\beta \frac{\lambda_{j, t+1}}{\lambda j, t}$ defines the discount factor.

To ensure that depositors are willing to supply funds to bankers in this set up the following incentive constraint must be satisfied:

$$
V_{j, t} \geq \phi L_{j, t}
$$

\footnotetext{
${ }^{6}$ This implies that on average a banker performs this role for a period equal to $\frac{1}{1-\sigma_{b}}$.
} 
i.e. the expected terminal wealth $V_{j, t}$ should be greater than the present value of divertible funds.

As shown in GK the recursive definition of the present discount value of net worth at the end of the period takes the following form:

$$
\begin{gathered}
V_{j, t}=v_{j, t} L_{j, t}+\eta_{j, t} N W_{j, t} \\
\eta_{j, t}=E_{t}\left\{\left(1-\sigma_{b}\right)+\beta_{s} \frac{\lambda_{j, t+1}}{\lambda_{j, t}} \sigma_{b} \eta_{j, t+1} \frac{N W_{j, t+1}}{N W_{j, t}}\right\} \\
v_{j, t}=E_{t}\left\{\beta_{s} \frac{\lambda_{j, t+1}}{\lambda_{j, t}}\left(1-\sigma_{b)}\right)\left(r_{t}^{\text {int. }}-r_{t}^{f}\right)+\beta_{s} \frac{\lambda_{j, t+1}}{\lambda_{j, t}} \sigma_{b} v_{j, t+1} \frac{L_{j, t+1}}{L_{j, t}}\right\}
\end{gathered}
$$

where $v_{t}^{k}$ is the expected discounted marginal gain to the banker of expanding non-financial claims by a unit (keeping net worth constant), $\eta_{t}$ defines the expected discounted value of having another unit of net worth (holding assets constant) and the banker's leverage ratio

$$
l e v_{j, t}=\frac{\eta_{j, t}}{\phi-v_{j, t}}
$$

limits the banker's access to households deposits, so that the incentive constraint 3 is satisfied.

Since in every period only a fraction $\sigma_{(1-h)}$ of bankers will survive, the net worth of surviving bankers, $N_{t}^{e}$, evolves according to:

$$
N W_{t}^{e}=\sigma_{b}\left\{\left(r_{t}^{\text {int. }}-r_{t}^{f}\right) l e v_{t-1}+\left(1+r_{t}^{f}\right)\right\} N W_{t-1}
$$

Simultaneously, the fraction $\left(1-\sigma_{b}\right)$ of new born-bankers receives from households of a constant fraction $\frac{\varrho_{b}}{\left(1-\sigma_{b}\right)}$ of the value of assets that exiting bankers had intermediated in their final period. Hence, the law of motion of the total net worth is

$$
N W_{t}=\sigma_{b}\left\{\left(r_{t}^{\text {int. }}-r_{t}^{f}\right) l e v_{t-1}+\left(1+r_{t}^{f}\right)\right\} N W_{t-1}+\varrho_{b} L_{t-1}
$$

\subsubsection{Retail branch}

Retail banks operate under a regime of monopolistic competition. Borrowers buy a composite CES basket of differentiated loans and the elasticity of substitution $\varepsilon_{b}$ among loan types defines retail banks' market power. 
Retail banks receive funds from the wholesale branch at the rate $r_{t}^{\text {int. }}$ and transform them into differentiated loans at no cost. As we discuss in the following sections, loans are then supplied to borrowers at a contractual rate $r_{t}^{k, b}$. Taking into account the fraction of defaults, this allows retails bank to earn the loan rate $r_{t}^{l}$, which is set as a a mark-up over the wholesale rate. Borrowers' demand for loans from bank $j$ may be conveniently represented as:

$$
L_{t}^{h}(j)=\left(\frac{r_{t}^{l}(j)}{r_{t}^{l}}\right)^{-\varepsilon^{b}} L_{t}^{I}
$$

where $L_{t}^{I}$ represents the aggregate demand for loans and $L_{t}^{h}(j)$ the demand of a single household for loans at bank $j$. We assume that to change $r_{t}^{l}(j)$ the retail bank must pay a quadratic adjustment cost: ${ }^{7}$

$$
\frac{k_{h}}{2}\left(\frac{r_{t}^{l}(j)}{r_{t-1}^{l}(j)}-1\right)^{2} r_{t}^{l}(j) L_{t}(j)
$$

The $j$ bank chooses $r_{t}^{l}(j)$ to solve :

$$
\max \sum_{t=0}^{\infty} \tilde{\Lambda}_{0, t}\left[r_{t}^{l}(j) L_{t}(j)-r_{t}^{i n t} L_{t}(j)-\frac{k_{h}}{2}\left(\frac{r_{t}^{l}(j)}{r_{t-1}^{l}(j)}-1\right)^{2} r_{t}^{l}(j) L_{t}(j)\right]
$$

subject to (6).

Assuming a symmetrical equilibrium, the first order condition of the problem yields the following equation:

$$
\begin{aligned}
1 & -\varepsilon_{b, t}+\frac{\varepsilon_{b, t}\left(r_{t}^{i n t .}\right)}{r_{t}^{l}}-k_{h}\left(\frac{r_{t}^{l}}{r_{t-1}^{l}}-1\right) \\
& +\left(\frac{r_{t+1}^{l}}{r_{t}^{l}}-1\right)\left(\frac{r_{t}^{l}}{r_{t-1}^{l}}-1\right) \frac{\gamma \tilde{\lambda}_{t+1}}{\tilde{\lambda}_{t}} k k h\left(\frac{r_{t+1}^{l}}{r_{t}^{l}}-1\right) \frac{L_{t+1}}{L_{t}}=0
\end{aligned}
$$

\footnotetext{
${ }^{7}$ For the sake of simplicity and without any significant implication for our results, we assume that adjustment costs are immaterial, so they do not enter the market clearing conditions defined below.
} 


\subsection{Borrowers}

In our framework $P_{h}$ is the house nominal price, $\delta$ is the housing depreciation rate and $L_{t}^{b},(b=s p, p)$, is the size of the loan. The borrower chooses $H_{t}^{b}$ and $L_{t}^{b}$ at time $t$. At the beginning of $t+1$ the idiosyncratic shock hits her housing stock. After the shock some households' members will default, while the rest shall fulfill their obligations. Defaulting decisions occur whenever the borrower's subjective valuation of her housing stock falls short of the value of her mortgage. We can therefore identify a threshold value $\bar{\omega}_{t+1}^{b}$ such that households characterized by $\omega_{t+1}<\bar{\omega}_{t+1}^{b}$ will default.

$$
\left(\bar{\omega}_{t+1}^{b}+\operatorname{stigma}^{b}\right) H_{t}^{b} P_{h, t+1}(1-\delta)=L_{t}^{b}\left(1+r_{t+1}^{k, b}\right)
$$

Note that stigma $a^{b}$ plays a key role in determining the defaulting decision. Subprimers follow a ruthless defaulting condition: they default when the expected value of their loan (mortgage) is larger than the present value of the housing stock, i.e. stigma $a^{s p}=0$. Default is less likely to happen for primers. Formally we model this condition by setting a stigma ${ }^{p}=$ stigma $>$ 0 parameter, so that primers' housing investment valuation depends on an additional component which is proportional to the value of the housing stock.

To solve the borrower's problem we must first define the real bank participation constraint. In our setting, banks' return is predetermined, namely the rate $r_{t}^{l}$ is agreed at time $t$ and paid in the following period, notwithstanding contingencies. This assumption entails that the risk is borne by borrowers only. However, this does not rule out the possibility that a bank suffers a net worth reduction due to a reduction in profits. Taking this into account we can write the participation constraint for the bank as:

$$
\begin{aligned}
\left(1+r_{t}^{l}\right) L_{t}^{b}= & \int_{0}^{\bar{\omega}_{t+1}^{b}} \omega_{t+1}(1-\mu)(1-\delta) P_{h, t+1} H_{t}^{b} f_{t+1}(\omega) d \omega \\
& +\int_{\bar{\omega}_{t+1}^{b}}^{\infty}\left(1+r_{t+1}^{k, b}\right) L_{t}^{b} f_{t+1}(\omega) d \omega
\end{aligned}
$$

The participation constraint reads as follows: the value of the housing stock being seized by banks combined with the value of the loans paid back by non-defaulters (right hand side of (11)) must be equal the pre-determined return on loans $\left(1+r_{t}^{l}\right) L_{t}^{b}$. Note that this equation does not hold in expectations, but it is always satisfied. This is possible because the rate paid 
on mortgages $r_{t+1}^{k, b}$ adjusts as to satisfy the constraint at any point in time. That means that in this model we are assuming that mortgage contracts last only one period and feature adjustable rates. However, the presence of rate stickiness might be seen as a shortcut that allows to mimic fixed rates.

We can now identify the financial contract between borrowers and lenders. The contract is identified by an amount of lending $L_{t}^{b}$ and a contractual mortgage rate $r_{t+1}^{k, b}$. We can simplify the borrower problem by using some definitions. Let

$$
G_{t+1}\left(\bar{\omega}_{t+1}^{b}\right) \equiv \int_{0}^{\bar{\omega}_{t+1}^{b}} \omega_{t+1} f_{t+1}(\omega) d \omega
$$

be the share of defaulters' housing stock that the bank expects to seize, gross of monitoring costs, and

$$
\bar{\omega}_{t}^{b} \int_{\bar{\omega}_{t}^{b}}^{\infty} f_{t}(\omega) d \omega
$$

the proportion of housing property that accrues to the bank from nondefaulting borrowers. In this case the total expected share of the housing value that would go to the bank gross of monitoring costs is:

$$
\Gamma_{t+1}\left(\bar{\omega}_{t+1}^{b}\right) \equiv \bar{\omega}_{t+1}^{b} \int_{\bar{\omega}_{t+1}^{b}}^{\infty} f_{t+1}(\omega) d \omega+G_{t+1}\left(\bar{\omega}_{t+1}^{b}\right) .
$$

Using the above definitions, plugging (10) into (11) and dividing everything by $P_{c, t}$ we can rewrite the participation constraint getting rid of the contractual rate $r_{t+1}^{k, b}$ :

$$
\left(1+r_{t}^{f}\right) l_{t}^{b}=\Gamma_{t+1}\left(\bar{\omega}_{t+1}^{b}\right)-\mu G_{t+1}\left(\bar{\omega}_{t+1}^{b}\right)+\left[1-F_{t+1}\left(\bar{\omega}_{t+1}^{b}\right)\right]\left(s t i g m a^{b}\right)(1-\delta) p_{h, t+1} H_{t}^{b} \pi_{t+1}
$$

Given that

$$
E_{t}\left(\omega_{t}\right)=\int_{0}^{\bar{\omega}_{t}^{b}} \omega_{t} f_{t}(\omega) d \omega+\int_{\bar{\omega}_{t}^{b}}^{\infty} \omega_{t} f_{t}(\omega) d \omega=1
$$

where

$$
\int_{\bar{\omega}_{t}^{b}}^{\infty} \omega_{t} f_{t}(\omega) d \omega=\left[1-G_{t}\left(\bar{\omega}_{t}^{b}\right)\right]
$$

we can determine the housing stock households are left with at time t: 


$$
\int_{\bar{\omega}_{t}^{b}}^{\infty} \omega_{t}(1-\delta) H_{t-1}^{b} P_{h, t} f_{t}(\omega) d \omega=\left[1-G_{t}\left(\bar{\omega}_{t}^{b}\right)\right](1-\delta) H_{t-1}^{b} P_{h, t}
$$

We can now write the budget constraint in nominal terms:

$$
\begin{aligned}
& C_{t}^{b} P_{c, t}+P_{h, t} H_{t}^{b}+L_{t-1}^{b}\left(1+r_{t}^{k}\right)\left[1-F_{t}\left(\bar{\omega}_{t}^{b}\right)\right] \\
& \quad=L_{t}^{b}+(1-\delta)\left[1-G_{t}\left(\bar{\omega}_{t}^{b}\right)\right] P_{h, t} H_{t-1}^{b}+\sum_{m} W_{m, t}^{b} N_{m, t}^{b}
\end{aligned}
$$

and therefore the the budget constraint in real terms reads as follows:

$$
C_{t}^{b}+p_{h, t} H_{t}^{b}+\frac{l_{t-1}^{b}}{\pi_{t}}\left(1+r_{t-1}^{l}\right)=l_{t}^{b}+(1-\delta)\left[1-\mu G_{t}\left(\bar{\omega}_{t}^{b}\right)\right] p_{h, t} H_{t-1}^{b}+\sum_{m} w_{m, t}^{b} N_{m, t}^{b}
$$

Borrowers maximize (1) with respect to $C_{t}^{b}, H_{t}^{b}, l_{t}^{b}$ and $\bar{\omega}_{t+1}^{b}$ subject to the budget constraint (17) and to the participation constraint (14).

The first order condition with respect to $C_{t}^{b}$ equates marginal utility from consumption $M U_{c, t}^{b}$ with the Lagrange multiplier from the budget constraint:

$$
M U_{c, t}^{b}=\lambda_{t}^{b}
$$

The first order condition with respect to $H_{t}^{b}$ defines the investment decisions in the housing sector:

$$
\begin{aligned}
\lambda_{t}^{b} p_{h, t}=M U_{h, t}^{b}+ & (1-\delta) \beta_{b} E_{t}\left[\left(1-\mu G_{t+1}\left(\bar{\omega}_{t+1}^{b}\right)\right) \lambda_{t+1}^{b} p_{h, t+1}\right. \\
& \left.+\gamma_{t+1}^{b}\left[\Gamma_{t+1}\left(\bar{\omega}_{t+1}^{b}\right)-\mu G_{t+1}\left(\bar{\omega}_{t+1}^{b}\right)\right] p_{h, t+1} \pi_{t+1}\right]
\end{aligned}
$$

where $M U_{h, t}^{b}$ is the marginal utility from housing services. Equation (19) deserves a closer scrutiny. This condition requires that the marginal gain from consumption equals the marginal gain from housing. That is not only given by the marginal utility of housing but also from the fact that housing can be sold in the next period and used to buy an additional unit of consumption and by the fact that it can be used as a collateral (latter term on the right).

The first order condition with respect to $l_{t}^{b}$ is given by:

$$
\lambda_{t}^{b}-\left(1+r_{t}^{l}\right) E_{t}\left[\frac{\lambda_{t+1}^{b}}{\pi_{t+1}} \beta_{b}+\gamma_{t+1}^{b}\right]=0
$$


where $\gamma_{t+1}^{s p}$ is the Lagrange multiplier of the bank participation constraint. This equation also reads as the Euler equation for borrowers and it states that the marginal utility from consumption today is higher than the marginal utility from consumption tomorrow when the borrowing constraint is binding $\left(\gamma_{t+1}^{s p}>0\right)$.

Finally, we have the first order condition with respect to the defaulting threshold:

$$
\begin{aligned}
& -\lambda_{t+1}^{b} \beta_{b} \mu G_{t+1}^{\prime}\left(\bar{\omega}_{t+1}^{b}\right) \\
& \quad+\gamma_{t+1}^{b}\left[\Gamma_{t+1}^{\prime}\left(\bar{\omega}_{t+1}^{b}\right)-\mu G_{t+1}^{\prime}\left(\bar{\omega}_{t+1}^{b}\right)-f_{t+1}\left(\bar{\omega}_{t+1}^{b}\right)(\text { stigma })^{b}\right] \pi_{t+1}=0
\end{aligned}
$$

Note that (21) is not expressed in expectations since $\bar{\omega}_{t+1}^{b}$ adjusts to ensure that the participation constraint (14) always holds with equality. This condition equates the marginal gain from a small increment in the defaulting threshold to the additional cost of defaulting. The former is given by the increase in the loan to value ratio, and it is bigger the larger is $\gamma_{t+1}^{b}$, i.e. the more the borrower is constrained. The latter is given by the marginal increase in the resources wasted by a higher rate of default. Indeed, $\mu G\left(\bar{\omega}_{t+1}^{b}\right)$ is the amount of monitoring costs, which are de iure paid by the lender, but de facto are borne by borrowers.

\subsection{Savers}

The problem of savers - that we denote with a $\sim$ is standard. They maximize (1) over $\tilde{C}_{t}, \tilde{H}_{t}$ and $\tilde{d}_{t}$ subject to the following budget constraint defined in real terms:

$$
\tilde{C}_{t}+p_{h, t}\left[\tilde{H}_{t}-\tilde{H}_{t-1}(1-\delta)\right]+\tilde{d}_{t}=\frac{\tilde{d}_{t-1}\left(1+r_{t-1}^{d}\right)}{\pi_{t}}+\tilde{w}_{t} \tilde{N}_{t}+\Pi_{t}^{f i}
$$

where $d_{t}$ is real deposits and $r_{t}^{d}$ the risk free rate earned on deposits and $\Pi_{t}^{f i}$ are profits rebated from firms and the banking sector.

The first order condition with respect to $\tilde{C}_{t}$ defines the Lagrange multiplier:

$$
\tilde{M} U_{c, t}=\tilde{\lambda}_{c, t}
$$

while that on $\tilde{H}_{t}$ defines housing investment:

$$
\tilde{\lambda}_{c, t} p_{h, t}=\tilde{M} U_{h, t}+\beta(1-\delta) E_{t}\left[p_{h, t+1} \tilde{\lambda}_{t+1}\right]
$$


Finally, the first order condition with respect to $\tilde{d}_{t}$ is given by a standard Euler Equation:

$$
\tilde{\lambda}_{t}=\tilde{\lambda}_{t+1} \beta \frac{\left(1+r_{t}^{d}\right)}{\pi_{t+1}}
$$




\subsection{Firms}

The economy is characterized by durable and non-durable goods producing firms, $m=(c, h)$. The two sectors will differ for the calibration and for the different degree of price stickiness. In particular, as highlighted by Carlstrom and Fuerst (2010), it seems implausible that house prices are sticky. Each sector $m$ includes both final and intermediate goods producers.

\subsection{Final Goods Producers}

For each sector $m$ we assume that a continuum of perfectly competitive firms produces the final good using a CES technology of this form:

$$
Y_{m, t}=\left(\int_{0}^{1} Y_{m, t}(i)^{\frac{\varepsilon_{m}-1}{\varepsilon_{m}}} d i\right)^{\frac{\varepsilon_{m}}{\varepsilon_{m}-1}}
$$

where $i \in[0,1]$ is the good produced by the intermediate goods producer firm $i$. Following the producer maximization problem we can derive the demand for intermediate goods:

$$
Y_{m, t}(i)=\left(\frac{P_{m, t}(i)}{P_{m, t}}\right)^{-\varepsilon_{m}} Y_{m, t}
$$

and the price index:

$$
P_{m, t}=\left(\int_{0}^{1} P_{m, t}(i)^{1-\varepsilon_{m}}\right)^{\frac{1}{1-\varepsilon_{m}}} d i
$$

\subsection{Intermediate Goods Producers}

A measure $i \in[0,1]$ of intermediate goods producers operates under monopolistic competition. The production function in the intermediate sector is:

$$
Y_{m, t}(i)=A_{m, t} N_{m, t}(i)
$$

where $A_{t}$ is a standard productivity parameter. Firms face quadratic costs of adjusting prices:

$$
A D J_{-} P_{t}(i)=\frac{\gamma_{m}}{2}\left(\frac{P_{m, t}(i)}{P_{m, t-1}(i)}-1\right)^{2} Y_{m, t}
$$


In addition, we follow Carlstrom and Fuerst (2010) introducing production adjustment costs in the housing sector. These authors argue that, if the model features wage stickiness, housing production is very sensitive to shocks, and adjustment costs greatly helps in matching data. Carlstrom and Fuerst (2010) introduce firm-level adjusting cost separating between the cost that a firm faces in adjusting the level of production and the cost the firm faces in changing the production level. Those are respectively:

$$
\begin{gathered}
P_{h, t} \phi_{1}^{h} \frac{Y_{h, s s}}{2}\left(\frac{Y_{h, t}-Y_{h, s s}}{Y_{h, s s}}\right)^{2} \\
P_{h, t} \phi_{2}^{h} \frac{Y_{h, s s}}{2}\left(\frac{Y_{h, t}-Y_{h, t-1}}{Y_{h, s s}}\right)^{2}
\end{gathered}
$$

In a symmetrical equilibrium, profit maximization yield the familiar New Keynesian Phillips curve for the consumption sector

$$
\begin{aligned}
\left(1-\varepsilon_{m}\right)+\varepsilon_{m} m c_{m, t}= & \gamma_{m, t}\left(\pi_{m, t}-1\right) \pi_{m, t} \\
& -\gamma_{m, t} E_{t}\left[\frac{\Lambda_{t+1}}{\Lambda t} \frac{P_{m, t+1}}{P_{m, t}} \frac{Y_{m, t+1}}{Y_{m, t}}\left(\pi_{m, t+1}-1\right) \pi_{m, t+1}\right]
\end{aligned}
$$

where

$$
\pi_{m, t}=\frac{P_{m, t}}{P_{m, t-1}}
$$

defines the gross inflatio rate.

Similarly, for the housing production sector we obtain

$$
\begin{aligned}
\left(1-\varepsilon_{m}\right)+\varepsilon_{m} m c^{r e a l}= & \gamma_{m} \pi_{t}\left(\pi_{t}-1\right)-\frac{\Lambda_{t+1}}{\Lambda_{t}} \gamma_{m} \frac{Y_{t+1}}{Y_{t}}\left(\pi_{t+1}\right)^{2}\left(\pi_{t+1}-1\right) \\
& -\varepsilon_{m} \phi_{1}^{h}\left(\frac{Y_{t}}{Y_{s s}}-1\right)-\varepsilon_{m} \phi_{2}^{h}\left(\frac{Y_{t}}{Y_{s s}}-\frac{Y_{t-1}}{Y_{s s}}\right) \\
& +\frac{\Lambda_{t+1}}{\Lambda_{t}} \varepsilon_{m} \phi_{2}^{h} \pi_{t+1}\left(\frac{Y_{t+1}}{Y_{s s}}-\frac{Y_{t}}{Y_{s s}}\right)
\end{aligned}
$$




\subsection{The Labor Market}

The labor market is modelled in a way similar to Iacoviello and Neri (2010) since we consider a union operating for each household group and for each sector. $^{8}$ We assume that unions face quadratic costs when adjusting the nominal wage:

$$
A C_{w, t}=\frac{\gamma_{w}}{2}\left(\frac{W_{t}}{W_{t-1}}-1\right)^{2} w_{t}
$$

Households offer homogeneous labor services to unions that differentiate labor and set their wages as a mark-up over their marginal rate of substitution. Labor services are then reassembled by labor packers that offer labor to goods producers. Solving the unions problem we have six conditions, two for each households'group. As an example we report the conditions for savers.

$$
\begin{aligned}
\frac{\tilde{w}_{c, t}}{\tilde{w}_{c, t-1}} \tilde{\gamma}_{w, c}\left(\frac{\tilde{w}_{c, t}}{\tilde{w}_{c, t-1}}-1\right)= & \gamma_{w, c} \frac{\gamma \tilde{\lambda}_{t+1}}{\tilde{\lambda}_{t}} \frac{\tilde{w}_{c, t+1}}{\tilde{w}_{c, t}} \frac{\tilde{w}_{c, t+1}}{\tilde{w}_{c, t}}\left(\frac{\tilde{w}_{c, t+1}}{\tilde{w}_{c, t}}-1\right) \\
& +\left(1-\varepsilon_{w c}\right) \tilde{N}_{c, t}+\tilde{N}_{c, t} \frac{\varepsilon_{w c}}{\tilde{w}_{c, t}} \frac{\tilde{v} \tilde{N}_{c, t}^{\tilde{\eta}}}{\tilde{\lambda}_{t}} \\
\frac{\tilde{w}_{h, t}}{\tilde{w}_{h, t-1}} \tilde{\gamma}_{w, c}\left(\frac{\tilde{w}_{h, t}}{\tilde{w}_{h, t-1}}-1\right)= & \gamma_{w, c} \frac{\gamma \tilde{\lambda}_{t+1}}{\tilde{\lambda}_{t}} \frac{\tilde{w}_{h, t+1}}{\tilde{w}_{h, t}} \frac{\tilde{w}_{h, t+1}}{\tilde{w}_{h, t}}\left(\frac{\tilde{w}_{h, t+1}}{\tilde{w}_{h, t}}-1\right) \\
& +\left(1-\varepsilon_{w d}\right) \tilde{N}_{h, t}+\tilde{N}_{h, t} \frac{\varepsilon_{w d}}{\tilde{w}_{h, t}} \frac{\tilde{v} \tilde{N}_{h, t}^{\tilde{\eta}}}{\tilde{\lambda}_{t}}
\end{aligned}
$$

\footnotetext{
${ }^{8}$ While wages can differ across sectors, the probability to readjust the wage is the same across household's groups.
} 


\subsection{Equilibrium Conditions}

Total nominal output in the economy is given by the sum of output in the non-durable and in the housing sector:

$$
Y_{t} P_{c, t}=Y_{c, t} P_{c, t}+Y_{h, t} P_{h, t}
$$

We define real output as follows:

$$
Y_{t}=Y_{c, t}+p_{h, t} Y_{h, t}
$$

where the real housing price is defined as $p_{h, t}=\frac{P_{h, t}}{P_{c, t}}$.

The market clearing condition in the non-durable sector requires total output in $c$ to be equal to aggregate demand:

$$
Y_{c, t}=(1-\xi) \tilde{C}_{t}+\xi(1-\vartheta) C_{t}^{s p}+\xi \vartheta C_{t}^{p}+\frac{\theta_{c}}{2}\left(\pi_{t}-1\right)^{2} Y_{c, t}
$$

In the housing sector, total output is equal to the total amount of investment carried out by each households' group:

$$
\begin{aligned}
Y_{h, t}= & (1-\xi)\left[\tilde{H}_{t}-(1-\delta) \tilde{H}_{t-1}\right]+\xi(1+\vartheta)\left[H_{t}^{s p}-\left(1-\mu G_{t}\left(\bar{\omega}_{t}^{s p}\right) H_{t-1}^{s p}\right)(1-\delta)\right] \\
& +\xi(\vartheta)\left[H_{t}^{p}-\left(1-\mu G_{t}\left(\bar{\omega}_{t}^{p}\right) H_{t-1}^{p}\right)(1-\delta)\right]+\frac{\theta_{d}}{2}\left(\pi_{t}-1\right)^{2} Y_{d, t}
\end{aligned}
$$

Notice that the equilibrium condition for housing investment is gross of monitoring costs.

With respect to the labor market the equilibrium condition requires the following equations for savers, subprimers and primers to be satisfied with equality:

$$
\begin{aligned}
\int_{0}^{1} & =\tilde{N}_{m, t}(\iota) d \iota \\
& =(1-\xi) \tilde{N}_{m, t} \\
\int_{0}^{1} & =N_{m, t}^{s p}(\iota) d \iota \\
& =\xi(1-\vartheta) N_{m, t}^{s p}
\end{aligned}
$$




$$
\begin{aligned}
\int_{0}^{1} & =N_{m, t}^{p}(\iota) d \iota \\
& =\xi \vartheta N_{m, t}^{p}
\end{aligned}
$$

Finally, the equilibrium condition in the credit market requires total loans to be equal to deposits plus aggregate banks' net worth:

$$
\xi(1-\vartheta) L_{t}^{s p}+\xi \vartheta L_{t}^{p}=(1-\xi) \tilde{D}_{t}+N W_{t}
$$

\subsection{Monetary Policy}

We consider a Central Bank seeking to control inflation and output through a Taylor Rule operating via changes in the nominal interest rate:

$$
\frac{1+r_{t}^{f}}{1+\bar{r}^{f}}=\left[\pi_{C, t}^{\phi_{\pi}}\right]^{1-\phi_{r}}\left[\frac{1+r_{t-1}^{f}}{1+\bar{r}^{f}}\right]^{\phi_{r}}\left[\left(\frac{Y_{t}}{Y_{t-1}}\right)^{\phi_{y}}\right]^{1-\phi_{r}}
$$

where $\bar{r}^{f}$ is the steady state risk free nominal interest rate, $\phi_{r}$ is the coefficient associated to the lagged interest rate, $\phi_{\pi}$ the coefficient associated to the inflation target and $\phi_{y}$ the coefficient that measures the response to changes in the output gap. ${ }^{9}$

\footnotetext{
${ }^{9}$ Notice that Wholesale banks face an infinitely elastic supply of funds at the policy rate $r^{f}$. Thus, by arbitrage, $r^{d}=r^{f}$.
} 


\section{Calibration}

The model is calibrated quarterly on U.S. macroeconomic data while targeting some key variables using microeconomic data at the household level. Following Justiniano et al. (2015) and Justiniano et al. (2016) the share of borrowers is set to $61 \%$, of which $36 \%$ are subprimers. In particular, this latter figure reflects the share of households with a Risk Score of 660 or lower in the FRBNY Consumer Credit Panel (CCP) ${ }^{10}$ while the former is derived from the Survey on Consumer Finances (SCF) and stems from the identification of borrowers as liquidity constrained agents. ${ }^{11}$ As in FL, the weight of housing in the utility function, $\alpha$, has been chosen to match a $8 \%$ share of housing over GDP in steady state. This measure reflects the combined share of residential and non residential fixed investment in structures in the U.S. economy for the period 2000-2007. ${ }^{12}$ Savers discount factor is set to 0.99, consistently with an annualized yearly risk free rate of $4 \%$. We calibrate the discount factor of borrowers, the standard deviation of the idiosyncratic shock, the monitoring costs and the stigma component to obtain in steady state the LTV ratios we find in the data and the rate of default for primers and subprimers recorded in the National Delinquency Survey. Namely, our target is the default rate in the first trimester of 2006, when, on the verge of the crisis the default for primers was equal to $0.77 \%$ and that of subprimers to $6.2 \%$. The loan to value ratio is equal to $84.5 \%$ for primers, while it is $52 \%$ for subprimers, consistently with the average LTV ratio for the U.S., which was equal to $75.7 \%$ between 1973 and 2008. The resulting value for the monitoring costs is 0.09 while the standard deviation of the idiosyncratic shocks is larger for subprimers (0.36) than for primers (0.067). The spread between the thirty year conventional mortgage rate and the interest rate on the U.S. Treasury thirty-year bond has been on average 150 basis point. In our calibration the spread is equal to $115 \mathrm{bp}$ for primers and $350 \mathrm{bp}$ for subprimers. This spread is the combination of two distinct features of model. First, banks set the risk free loan rate $r_{t}^{l}$ as a mark up over the wholesale rate, which is ultimately pinned down by the policy rate. Assuming an elasticity of substitution of 5 , the mark-up is equal to $20 \%$, implying a $100 \mathrm{bp}$

\footnotetext{
${ }^{10}$ The value refers to 1999 which is the first year available for the study.

${ }^{11}$ Liquidity constrained agents are defined as those with an amount of liquid assets lower than two months of their total income.

${ }^{12} \mathrm{As}$ noted by FL, this share has been historically lower on average, being equal to $5 \%$ over the period 1960-2009.
} 
spread between the two rates. ${ }^{13}$ Second, the presence of the agency problem between borrowers and banks, accounts for the spread between the risk free loan rate and the contractual rate, which is equal to $5.1 \%$ for primers and $8.5 \%$ for subprimers.

The value of the inverse of the Frisch elasticity of labor supply is 1 and the weight of labor in the utility function is households specific and calibrated such that each individual agent chooses to work $1 / 3$ of her available time in steady state, while the parameter that measures habits in consumption is equal to 0.8. $\chi_{\imath}$ - the parameter measuring the elasticity of substitution between housing and consumption in the consumption bundle - is calibrated following Flavin and Nakagawa (2008). Furthermore, we allow for a distinct calibration for borrowers (0.59) and savers (0.45) implying a different degree of substitutability for the two classes of households. This assumption reflects to a certain extent the segmentation of the housing sector in the U.S., implying that a shock originating in the subprimers market has limited repercussions on the savers housing market.

The elasticity of substitution in both sectors and in the wage Phillips curve are chosen to be consistent with a mark-up of $15 \%$. We calibrate $\gamma_{c}$ and $\gamma_{w, m}$ to replicate the Calvo pricing parameterization that would imply average contract durations of four quarters. House prices are instead left perfectly flexible as in most of the literature on housing, therefore we set $\gamma_{h}=0 .{ }^{14}$ Moving to the bank-specific parameters, we closely follow GK. The overall leverage for the banking sector is equal to 10, implying a fraction of loans that can be diverted of 0.23 , the transfers to entering bankers to $\rho_{b}=0.00017$, while the share of bankers that does not need to be replaced is equal to 0.973 implying an average survival rate of $\frac{1}{1-\sigma}=37$.

Finally, the parameters in the monetary policy rule are based on Iacoviello and Neri (2010).

\footnotetext{
${ }^{13}$ This value is also in line with Gertler and Karadi (2011)

${ }^{14}$ Under our modellization of the labor market the presence of different discount factors for borrowers and savers implies slightly different values for the parameters related to the cost of adjusting wages.
} 
Table 1: Calibrated Parameters

\begin{tabular}{ccc}
\hline Parameter Name & Value & Description \\
\hline \hline$\eta_{\imath}$ & 1 & Inverse elasticity of labor supply \\
$\beta_{s}$ & 0.99 & Savers discount factor \\
$\delta_{d}$ & 0.0025 & Rate of depreciation of housing \\
$\beta_{b}$ & 0.98 & Borrowers discount factor \\
$\varepsilon_{c}$ & 7.5 & Elasticity of substitution for C goods \\
$\varepsilon_{d}$ & 7.5 & Elasticity of substitution for D goods \\
$\varepsilon_{w c}$ & 7.5 & Elasticity of substitution labor in C \\
$\varepsilon_{w d}$ & 7.5 & Elasticity of substitution labor in D \\
$\phi_{\pi}$ & 1.44 & Taylor rule sensitivity to inflation \\
$\phi_{y}$ & 0.8 & Taylor rule sensitivity to output \\
$\phi_{R}$ & 0.6 & Taylor rule smoothing \\
$\rho_{e}$ & 0.0 & Autoregressive parameter shock TR \\
$\xi$ & 0.61 & Share of constrained agents \\
$\vartheta$ & 0.36 & Share of subprimers \\
$\chi_{b}$ & 0.59 & Elasticity of sub. utiltiy (borr.) \\
$\chi_{s}$ & 0.45 & Elasticity of sub. utiltiy (borr.) \\
$\varphi_{D 1}$ & 0.03 & Adjustment costs. housing (SR) \\
$\varphi_{D 1}$ & 0.1 & Adjustment costs. housing (LR) \\
$b_{h}$ & 0.8 & Habits in consumption paramter \\
$\mu$ & 0.095 & Monitoring costs \\
$\sigma^{p}$ & 0.067 & Standard deviation id. shock primers \\
$\sigma^{p}$ & 0.36 & Standard deviation id. shock subprimers \\
$\rho_{s}$ & 0.9 & Autocorrelation idios. shock \\
$\varepsilon_{b}$ & 5 & Elasticity banks loans \\
$\widehat{\varphi}$ & 10 & Leverage ratio \\
$k_{b}$ & 10.63 & Adjusting cost param. banks \\
$k_{h}$ & 13.58 & Adjusting cost param. hous. loan dem \\
$\sigma_{b a n k s}$ & 0.973 & Survival rate of bankers \\
$\rho_{b a n k s}$ & 0.00017 & Fraction of loans that can be diverted \\
$\phi$ & 0.23 & \\
& & \\
\hline \hline
\end{tabular}

Table 1: Notes: annualized value of parameters are reported 


\section{Crisis Experiments}

The crisis experiments are triggered by a shock to the standard deviation of the idiosyncratic disturbance that hits subprimers' housing investment. The shock evolves according to the following process:

$$
\ln \frac{\sigma_{\omega^{s p}, t}}{\bar{\sigma}_{\omega^{s p}}}=\rho_{\sigma_{\omega^{s p}}} \ln \frac{\sigma_{\omega^{s p}, t-1}}{\bar{\sigma}_{\omega^{s p}}}+\varepsilon_{\sigma_{\omega} s p, t}
$$

where $\bar{\sigma}_{\omega^{s p}}$ is the steady state value of the standard deviation and $\rho_{\sigma_{\omega^{s p}}}$ is the serial correlation coefficient. $\varepsilon_{\sigma_{\omega} s p, t}$ is an i.i.d. shock with a standard deviation equal to $\sigma_{\sigma_{\omega} s p}$ and a mean of zero. A mean preserving increase in the standard deviation of the idiosyncratic shock brings about an increase in the rate of default for any given threshold level $\bar{\omega} \cdot{ }^{15}$ Figure 7 shows two lognormal distributions characterized by the same mean and a different standard deviations as an illustrative example.

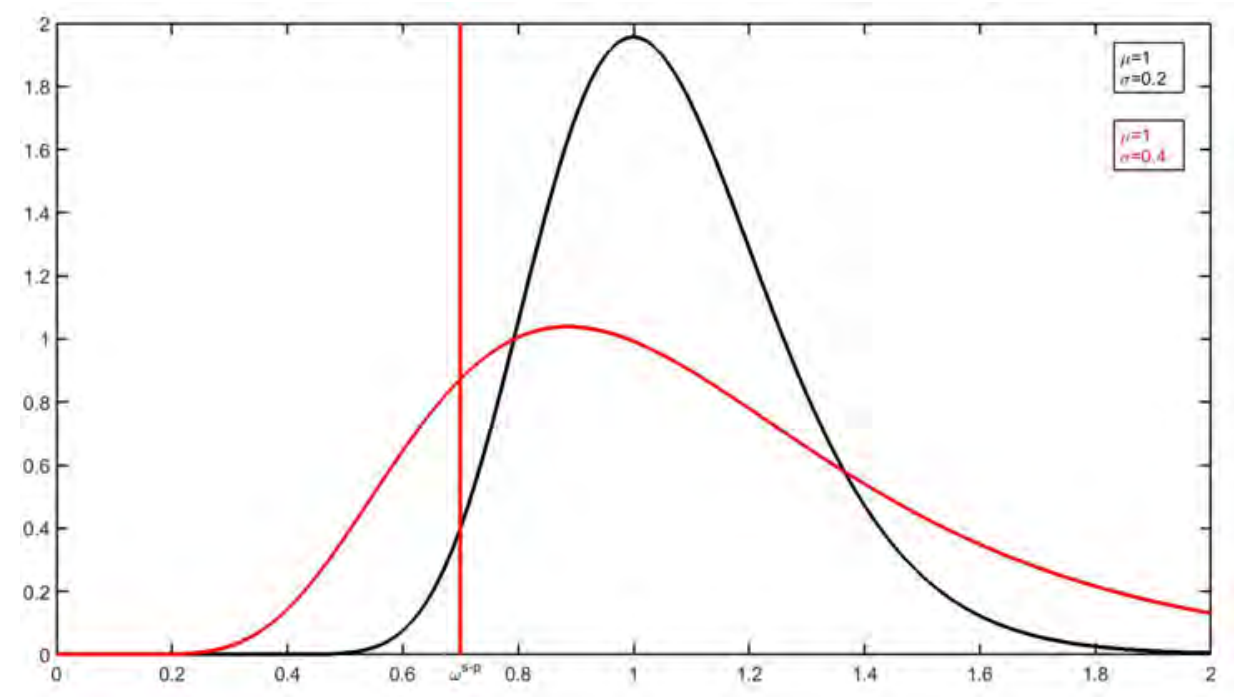

Figure 7: The log normal distribution for two different values of the standard deviation.

An increase in subprimers' risk entails a spike in the contractual rate of mortgages paid by subprimers. We calibrate the shock in order to get

\footnotetext{
${ }^{15}$ This result is a direct consequence of the properties of the log-normal distribution, where an increase in the standard deviation thickens the tails of the distribution.
} 
on impact an increase of subprimers' default rate equal to $16.42 \%$, which corresponds to the percentage of seriously delinquent loans in the first quarter of 2008, when the financial crisis started.

It should be noted, however, that the subprime crisis was also associated to a systemic increase in bank risk, exemplified by the Lehman Brothers bankruptcy. This point is raised in Eichengreen et al. (2012) who forcefully argue that banks systemic risk "rose to exceptional levels between the outbreak of the Subprime Crisis and the rescue of Bear Stearns, reflecting increased diffuse sense that credit risk was increasing. The period following the failure of Lehman Brothers then saw a further increase in those interdependencies, reflecting heightened funding and counterparty risk."

In principle it is difficult to incorporate such shocks in our model because the financial contract between the bank and the borrower almost insulates the bank's balance sheet. For this reason GK consider an adverse bank balance sheet shock. The innovation here is that we introduce the possibility that such shock is correlated with the shock to subprimers risk. Considering banks net worth, we introduce a shock $A_{n w, t}$ which evolves as an $\mathrm{AR}(1)$ process.

$$
N W_{t}=\sigma_{b}\left[l e v_{t-1}\left(r_{t}^{i n t .}-r_{t}^{f}\right)+\left(1+r_{t}^{f}\right)\right] N W_{t-1} A_{n w, t}+\varrho L_{t-1}
$$

As stated above, we allow this shock to be correlated with $\varepsilon_{\sigma_{\omega^{s p}, t}}$, and choose a calibration that matches the initial decline in banks net worth reported by GK.

\subsection{A Shock to the Standard Deviation of Subprimers' Idiosyncratic Risk}

Figure 8 shows the impulse response to a shock on the standard deviation of subprimers housing investment risk. The overall effect on the economy as well as the contagion effect to primers changes dramatically if we allow the shock to housing investment to be correlated to the shock to banks' net worth. The initial shock is immediately matched by larger risk premiums on mortgages. As financing loans becomes more expensive, subprimers respond by cutting consumption of both durable and non-durable goods. This mechanism, which mainly affects subprimers' housing demand, is exacerbated by declining house prices that reduce the value of collateral and by the fall in the loan to value ratio. Bank contagion, captured by the correlation between subprime risk 
shock and banks' net worth shock, appears to be a game changer. In fact the fall in housing consumption goes from $-10 \%$ to almost $-60 \%$.

Banks net worth falls by about $60 \%$, an amount which is still limited relative to what was observed in the US between 2007 and 2008, as documented in Figure 4. The model is able to reproduce a contagion effect from subprimers to primers that works via worsened banking condition. Specifically, default rates, and particularly risk premia, rise not only for subprimers but also for primers who, notwithstanding the decline in the risk free rate required by banks, face tighter financing condition and cut consumption of both housing and of non-durable goods. The shock also brings about a strong decline in the policy rate which gets close to the zero lower bound.

Our conclusions about the importance of bank contagion brings support to Bernanke (2010) view that weak regulation and insufficient supervision where at the roots of the financial crisis.. In fact we document that the perceived increase in subprimers risk is per se insufficient to generate a large crisis, which occurs when the initial shock is amplified because households associate it to a worse agency problem faced by commercial banks.

The magnitude of the response of real variables to the shock depends on the calibration of some key parameters. We assumed that the shock to banks' net worth is correlated to the increase in housing investment. This assumption is necessary because the model is not able to account endogenously for some important interlinkages between borrowers risk and banks balance sheets. However, as we show in Figure 9, it would be possible to obtain a similar decline in housing investment by removing completely the correlation between the two shocks and reducing the parameters measuring the adjustment costs in the housing sector. It should be noted, however, that in this case it would be impossible to match the near collapse in banks net worth that was observed during the financial crisis.

Other key parameters for our results are the elasticity of substitution between housing and consumption for savers and the parameter measuring habits in consumption. In figures 10 and ?? in the Appendix, we present robustness checks for the value of those parameters.

\section{Conclusion}

The recent crisis that originated in the U.S. residential market underscored the importance of credit frictions. Our contribution introduces frictions on 
both sides of the credit relationship. We do this by modelling subprime borrowers, which differ from primers for their higher rate of default, lower loan-to-value ratio and higher contractual mortgage rates. The propagation of the shock to the real economy is crucially affected by the "contagion" effect on the net worth of banks. Stickier bank rates exacerbate the contagion effect that goes from subprimers to primers.

Our work bears two important implications. The first one is that, in contrast with a popular wisdom developed in the aftermath of the crisis, linearized DSGE models have the potential to replicate the financial crisis effects without imposing particularly large shocks onto the economy. The second one concerns the importance of financial regulation. We document that the perceived increase in subprimers risk is per se insufficient to generate a large crisis, which in fact occurs when the initial shock reverberates through its effect on the net worth of financial intermediaries. This is broadly in line with the view that a regulatory failure greatly amplified the financial crisis. One crucial development would be to dig deeper into the connections between the borrowers' and the commercial banks' agency problems. We leave this for future research. 

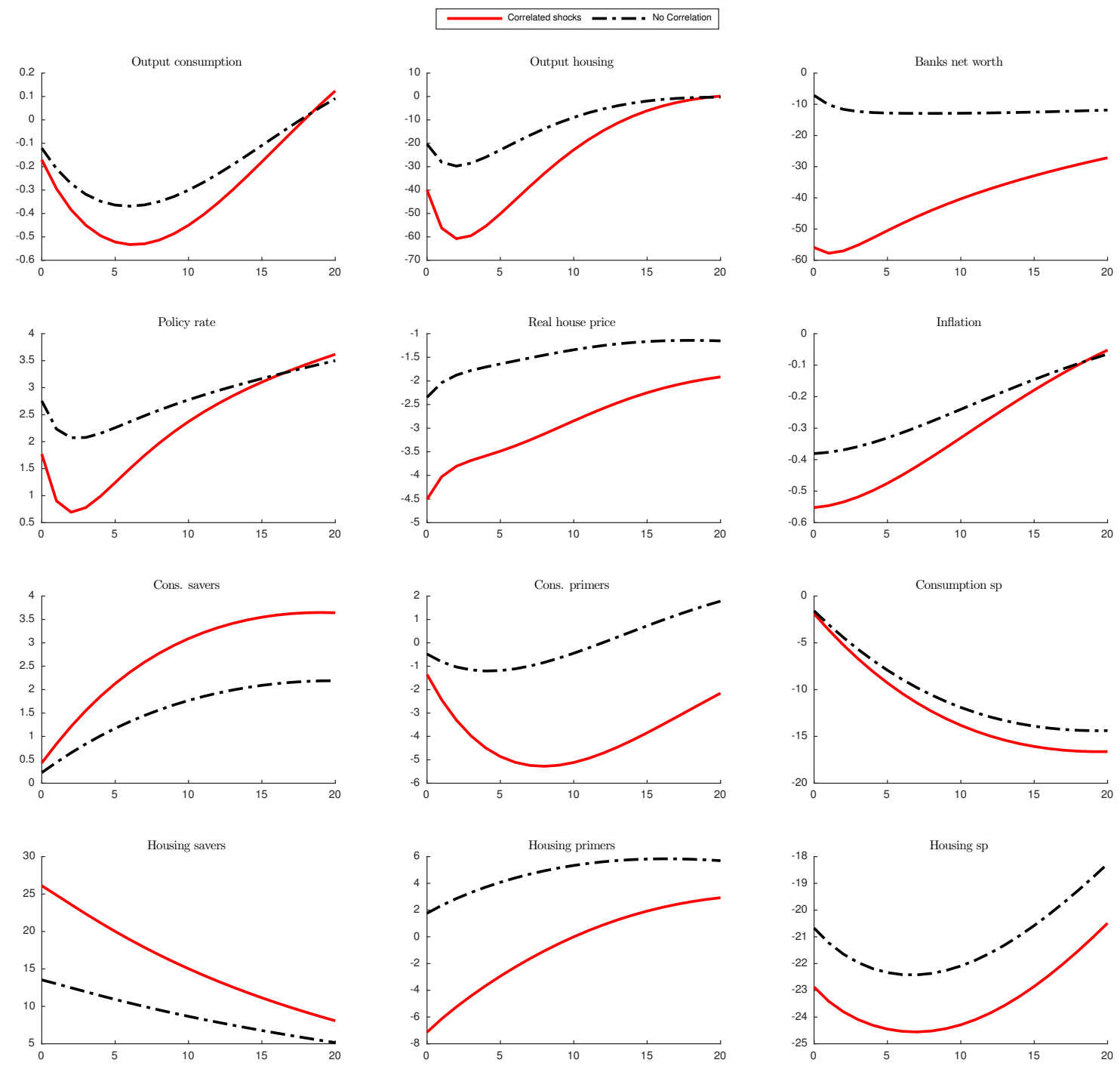

Figure 8: Comparison - shock to the standard deviation of subprimers idiosyncratic shock. All variable are expressed as a percentage deviation from steady state. Interest rates, default rates and external finance premia are instead annualized levels. 
A Appendix 

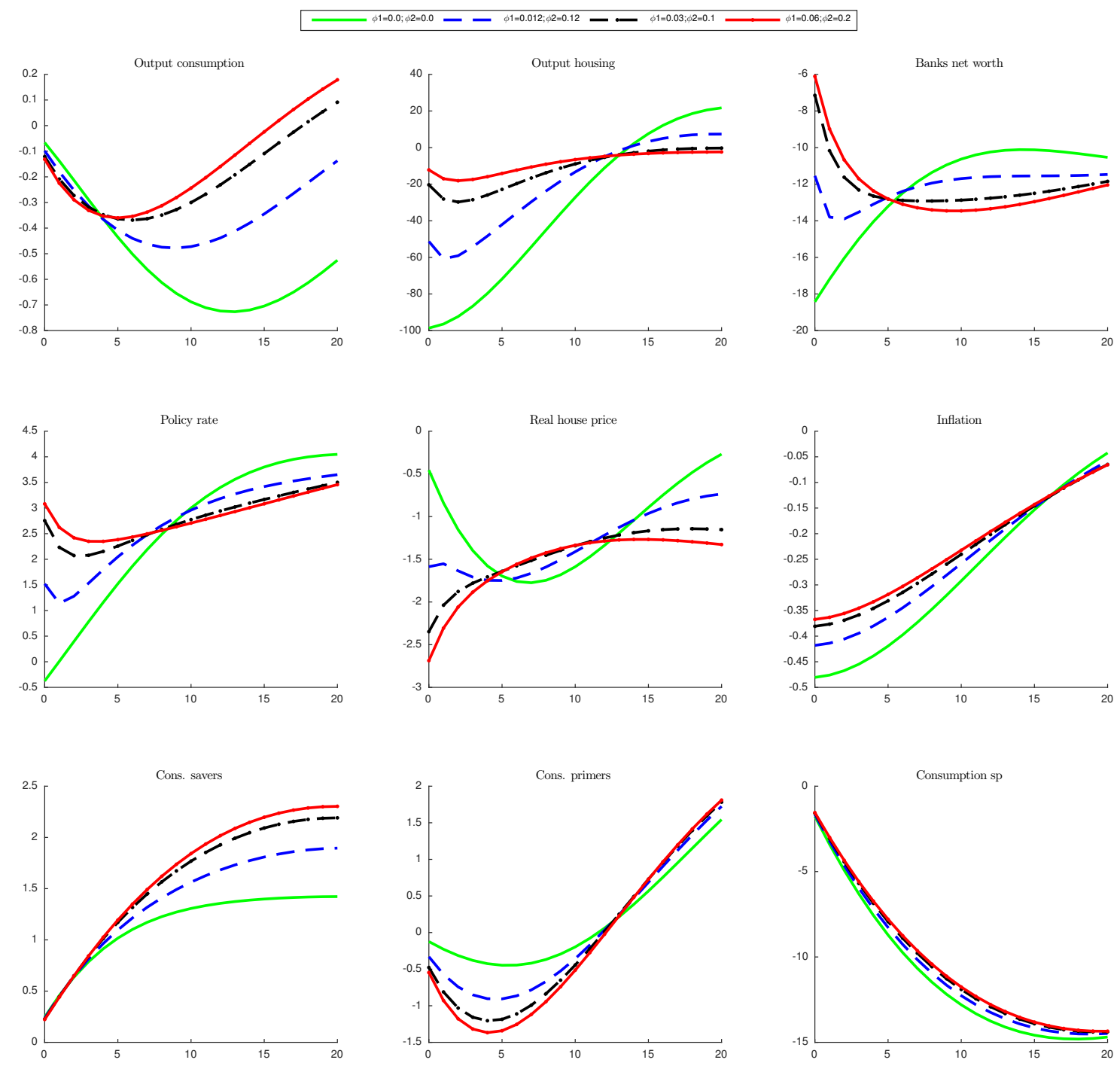

Figure 9: Robustness: housing investment adjustment costs - shock to the standard deviation of subprimers idiosyncratic shock. All variable are expressed as a percentage deviation from steady state. Interest rates, default rates and external finance premia are instead annualized levels. 

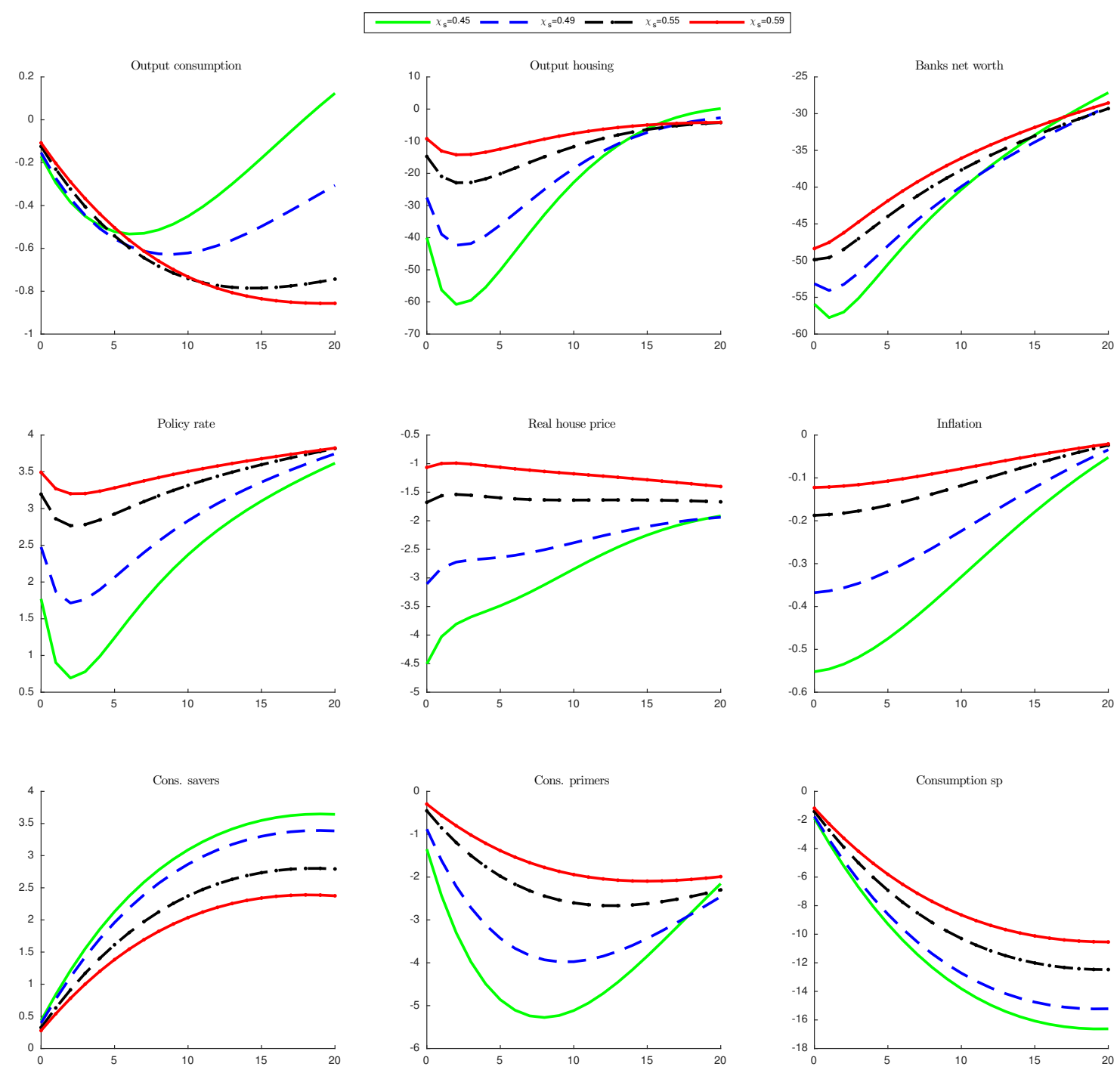

Figure 10: Robustness check: elasticity of substitution savers; correlated shocks - shock to the standard deviation of subprimers idiosyncratic shock. All variable are expressed as a percentage deviation from steady state. Interest rates, default rates and external finance premia are instead annualized levels. 


\section{References}

Adrian, T. and Shin, H. S. (2010). The Changing Nature of Financial Intermediation and the Financial Crisis of 20072009. Annual Review of Economics, 2(1):603-618.

Bajari, P., Chu, C. S., and Park, M. (2008). An Empirical Model of Subprime Mortgage Default From 2000 to 2007. National Bureau of Economic Research Working Paper Series, 14625.

Bernanke, B. (2010). Monetary policy and the housing bubble. A speech at the Annual Meeting of the American Economic Association, Atlanta, Georgia, January 3, 2010.

Bernanke, B. S. and Gertler, M. (1986). Agency costs, collateral, and business fluctuations. Proceedings.

Bernanke, B. S., Gertler, M., and Gilchrist, S. (1999). The financial accelerator in a quantitative business cycle framework. In Handbook of Macroeconomics, volume 1, Part C, pages 1341-1393. Elsevier.

Boissay, F., Collard, F., and Smets, F. (2016). Booms and Banking Crises. Journal of Political Economy, 124(2):489-538.

BrzozaBrzezina, M. and Kolasa, M. (2013). Bayesian Evaluation of DSGE Models with Financial Frictions. Journal of Money, Credit and Banking, 45(8):1451-1476.

Carlstrom, C. T. and Fuerst, T. S. (1997). Agency Costs, Net Worth, and Business Fluctuations: A Computable General Equilibrium Analysis.

Carlstrom, C. T. and Fuerst, T. S. (2010). Nominal Rigidities, Residential Investment, and Adjustment Costs. Macroeconomic Dynamics, 14(01):136.

Cerra, V. and Saxena, S. C. (2008). Growth Dynamics: The Myth of Economic Recovery. American Economic Review, 98(1):439-457.

Chomsisengphet, S. and Pennington-Cross, A. (2006). The evolution of the subprime mortgage market. FRB of St. Louis Review, (Jan):31-56.

Demyanyk, Y. and Hemert, O. V. (2011). Understanding the Subprime Mortgage Crisis. Review of Financial Studies, 24(6):1848-1880. 
Diamond, D. W. and Rajan, R. G. (2009). The Credit Crisis: Conjectures about Causes and Remedies. American Economic Review, 99(2):606-610.

Eichengreen, B., Mody, A., Nedeljkovic, M., and Sarno, L. (2012). How the Subprime Crisis went global: Evidence from bank credit default swap spreads. Journal of International Money and Finance, 31(5):1299-1318.

Federal Reserve Bank of San Francisco (2007). The Subprime Mortgage Market 2007 Annual Report. Technical report, Federal Reserve Bank of San Francisco.

Flavin, M. and Nakagawa, S. (2008). A Model of Housing in the Presence of Adjustment Costs: a Structural Interpretation of abit Persistence . American Economic Review, 98(1):474-495.

Foote, C. L., Gerardi, K., and Willen, P. S. (2008). Negative equity and foreclosure: Theory and evidence. Journal of Urban Economics, 64(2):234245.

Foote, C. L., Loewenstein, L., and Willen, P. S. (2016). Cross-Sectional Patterns of Mortgage Debt during the Housing Boom: Evidence and Implications. NBER Working Papers 22985, National Bureau of Economic Research, Inc.

Forlati, C. and Lambertini, L. (2011). Risky mortgages in a DSGE model. International Journal of Central Banking, 7(1):285-335.

Gerali, A., Neri, S., Sessa, L., and Signoretti, F. M. (2010). Credit and Banking in a DSGE Model of the Euro Area. Journal of Money, Credit and Banking, 42(s1):107-141.

Gertler, M. and Karadi, P. (2011). A model of unconventional monetary policy. Journal of Monetary Economics, 58(1):17-34.

Grodecka, A. (2016). Subprime Borrowers, Securitization and the Transmission of Business Cycles. Working Paper Series.

Guiso, L., Sapienza, P., and Zingales, L. (2013). The determinants of attitudes toward strategic default on mortgages. Journal of Finance, 68(4):1473-1515. 
Iacoviello, M. (2005). House Prices, Borrowing Constraints, and Monetary Policy in the Business Cycle. The American Economic Review, 95(3):739764.

Iacoviello, M. and Neri, S. (2010). Housing Market Spillovers: Evidence from an Estimated DSGE Model. American Economic Journal: Macroeconomics, 2(2):125-164.

Justiniano, A., Primiceri, G. E., and Tambalotti, A. (2015). Credit supply and the housing boom. Working Paper, (March 2014):1-41.

Justiniano, A., Primiceri, G. E., and Tambalotti, A. (2016). A simple model of subprime borrowers and credit growth. Staff Reports.

Kiyotaki, N. and Moore, J. (1997). Credit Cycles. Journal of Political Economy, 105(2):211-48.

Lind, J., Smets, F., and Wouters, R. (2016). Challenges for Central Banks' Macro Models. CEPR Discussion Papers 11405, C.E.P.R. Discussion Papers.

Pataracchia, B., Raciborski, R., Ratto, M., and Roeger, W. (2013). Endogenous housing risk in an estimated DSGE model of the Euro Area. European Economy - Economic Papers.

Smets, F. and Wouters, R. (2007). Shocks and Frictions in US Business Cycles: A Bayesian DSGE Approach. American Economic Review, 97(3):586606 .

Suh, H. and Walker, T. B. (2016). Taking financial frictions to the data. Journal of Economic Dynamics and Control, 64(C):39-65.

Townsend, R. M. (1979). Optimal contracts and competitive markets with costly state verification. Journal of Economic Theory, 21(2):265-293. 